\title{
Innovative application of an implantable venous access system in the portal vein: technique, results and complications in three dogs
}

Kiona S. de Nies ${ }^{* \dagger} \mathbb{D}$, Hedwig S. Kruitwagen ${ }^{\dagger}$, Giora van Straten, Leonie W. L. van Bruggen, Joris H. Robben, Baukje A. Schotanus, les Akkerdaas and Anne Kummeling

\begin{abstract}
Background: Vascular access port (VAP) systems are widely used in human medicine to provide long-term venous access. However, in veterinary medicine the use of VAP systems is not common practice and publications on their potential applications have been limited. A VAP system was used as part of an experimental study on liver regeneration and implanted in the canine portal vein to create direct access to the portal venous circulation of the liver. The aim of the present study is to describe the surgical technique, its use, and the complications of a VAP system in three research dogs.

Results: The VAP system was successfully used for the intraoperative measurement of portal blood pressure, the administration of cell suspensions, and the collection of portal venous blood samples. Long-term complications consisted of dislocation of the VAP system in one dog (2 months after implantation) and thrombus formation at the catheter tip in two dogs (3 months after implantation). Both complications prevented further use of the VAP but had no adverse clinical implications.

Conclusions: This pilot study suggests that the VAP system is an effective and safe technique to obtain long term access to the portal venous system in dogs. However, complications with port detachment and thrombosis may limit long term use of VAPs in the portal system of dogs.
\end{abstract}

Keywords: Dogs, Implant, Portal vein, Thrombus, Vascular access port

\section{Background}

This study describes a novel use in dogs of a vascular access port (VAP) surgically implanted into the portal vein to create direct access to the portal venous circulation of the liver. Vascular access port systems are widely used in human medicine to provide long term central venous access in patients who require comprehensive intravenous fluid therapy, multiple administrations of medication or repeated blood sampling. In people, they are commonly implanted in the superior vena cava via a subclavian,

\footnotetext{
*Correspondence: k.s.denies@gmail.com

${ }^{\dagger}$ Kiona S. de Nies and Hedwig S. Kruitwagen contributed equally to this work.

Faculty of Veterinary Medicine, Departement of Clinical Sciences of

Companion Animals, Utrecht University, Yalelaan 108, 3584, CM, Utrecht, The Netherlands
}

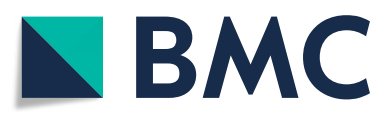

(c) The Author(s). 2019 Open Access This article is distributed under the terms of the Creative Commons Attribution 4.0 International License (http://creativecommons.org/licenses/by/4.0/), which permits unrestricted use, distribution, and reproduction in any medium, provided you give appropriate credit to the original author(s) and the source, provide a link to the Creative Commons license, and indicate if changes were made. The Creative Commons Public Domain Dedication waiver (http://creativecommons.org/publicdomain/zero/1.0/) applies to the data made available in this article, unless otherwise stated. the use of VAP systems is not common practice and literature on applications has been limited. Due to the reduced risk of infection, the limited chance for dislodgement and the ability to provide minimally invasive vascular access for repeated and long-term use, implantable VAP systems were previously suggested for both animal and human use [4-6]. VAP systems in the dog and cat can be valuable tools in experimental research, but also have clinical potential in veterinary medicine [4, 7-10]. VAP systems are described to be useful for chronic intravenous drug therapy, long-term use of chemotherapeutics and blood sampling [4, 11, 12]. Also, VAP systems were used in radiotherapy 
protocols requiring frequent anaesthesia to provide long-term venous access [5-7].

VAP implantation in the portal vein was advocated for regional chemotherapy of liver metastasis [2]. Permanent portal vein catheterization using a VAP was described in a human case series of repeated hepatocyte transplantations via the portal vein [8]. Use of VAP systems in canine portal veins has not been reported yet, as far as the authors know.

A VAP system in dogs has been evaluated as part of a research project in which liver cells were transplanted into the liver via the portal vein 'unpublished observations by H.S. Kruitwagen et al.'. The VAP system was intended to provide long-term, low-invasive portal venous access for the administration of cell suspensions and the collection of portal venous blood samples. The possibilities for direct measurement of portal venous blood pressure were also explored. The aim of this preliminary report is to describe the surgical technique, results, and complications of a VAP system in three dogs.

\section{Methods}

Study design

All procedures were approved by Utrecht University's Ethical Committee, as required under Dutch legislation (DEC number 2014.III.12.112) and performed at the Utrecht University Clinic for Companion Animals. Three research dogs were instrumented with the VAP system and the system was evaluated for a subsequent period of 5 months. After surgical implantation, the VAP system was used for intravenous infusion of liver cells intraoperatively and once daily for 2 days after surgery. The VAP system was also used for direct intraoperative measurement of portal venous pressure.

\section{Dogs}

Venous access port systems were implanted in three Beagle-Bedlington terrier crossbreeds with copper toxicosis due to COMMD1 deficiency [9]. Dog no. 1 was an intact male (5 years, $15.0 \mathrm{~kg}$ ), dog no. 2 an intact male (8 months, $15.5 \mathrm{~kg})$, and dog no. 3 an intact female $(8$ months, $10.6 \mathrm{~kg}$ ).

\section{Anaesthesia and monitoring}

Pre-operatively, all dogs received cefazolin $20 \mathrm{mg} / \mathrm{kg}$ IV (Kefzol, Eurocept International B.V., Ankeveen, The Netherlands). The dogs were premedicated with glycopyrrolate $0.01 \mathrm{mg} / \mathrm{kg}$ IM (Robinul $0.2 \mathrm{mg} / \mathrm{mL}$ injection, Riemser Pharma GmbH, Greifswald, Deutschland) and methadone $0.5 \mathrm{mg} / \mathrm{kg}$ IV (Comfortan $10 \mathrm{mg} / \mathrm{mL}$, Dechra, Bladel, The Netherlands). Propofol 1-4 mg/kg dosed to effect IV (Propofol 1\%, MC Fresenius Kabi, Zeist, The Netherlands) was used for induction. After intubation, general anaesthesia was maintained with isoflurane dosed to effect in a mixture of oxygen and air 1:1 and fentanyl continuous rate infusion $10-20 \mu \mathrm{g} / \mathrm{kg} / \mathrm{h}$ CRI (Fentanyl $0.05 \mathrm{mg} / \mathrm{mL}$, Bipharma, Almere, The Netherlands).

Postoperatively, the dogs were admitted to the intensive care unit for analgesia and monitoring. A clinical examination including abdominal circumference and central venous pressure measurements were performed every 4 hrs for 3 days. Mean arterial pressure was monitored via an intra-arterial line for at least $24 \mathrm{~h}$ postoperatively. Venous blood analysis was performed preoperatively, and 1 day, 2 days, 3 days, 1 week, 1 month, and 3 months post-operatively. Blood was sampled through the jugular catheter for the first three postoperative days and at later time points by venipuncture and was analysed for the following parameters: haematocrit, platelet count, activated partial thromboplastin time (aPTT), prothrombin time (PT), fibrinogen, total protein and albumin. Dogs received postoperative pain medication, initially consisting of fentanyl $3-5 \mu \mathrm{g} / \mathrm{kg} / \mathrm{h}$ CRI (Fentanyl, Bipharma, Almere, The Netherlands) and ketamine 3-5 $\mu \mathrm{g} / \mathrm{kg} / \mathrm{min}$ CRI (Narketan, Vetoquinol, 'sHertogenbosch, The Netherlands) to effect. After two to 3 days analgesia was continued for 3-5 days with tramadol $3-5 \mathrm{mg} / \mathrm{kg}$ four times daily per os (Tramadol $\mathrm{HCl}$, Centrafarm, Etten-Leur, The Netherlands). As part of the liver cell transplantation protocol, dogs received cyclosporine $6.25 \mathrm{mg} / \mathrm{kg}$ two times daily per os (Sporimune, AST Farma, Oudewater, The Netherlands) from the day before surgery until 3 months post-operatively.

\section{Surgery}

First, the implantation of the VAP system was practiced on two fresh cadavers of female mixed breed dogs (28 $\mathrm{kg}$ ), euthanized for non-related medical experiments (surplus material, Utrecht University 3R-policy). The surgical protocol was then applied to the three experimental dogs. All surgeries were performed by the same surgeons. A midline celiotomy was performed in dorsal recumbency and the falciform ligament was removed after cranial ligation. A left lateral hepatic lobectomy was performed as part of the liver cell transplantation study using double ligation of the large vessels near the hilus of the lobe with polydioxanone (PDS 0, Johnson \& Johnson International, Amersfoort, The Netherlands) and additional electrocoagulation to seal the parenchyma peripheral to the ligated vessels.

The VAP system used was a PORT-A-CATH II POWER system (reference number: 21-4477-24, Smiths Medical Nederland B.V., Rosmalen, The Netherlands) that consisted of a polyurethane catheter with an outer diameter of $1.9 \mathrm{~mm}$ (5.8 Fr), a titanium connector and a single lumen portal made of polysulfone and titanium. The priming volume was provided by the manufacturer and manually confirmed pre-operatively. The volume 
amount of the catheter + portal $=0.7+0.3 \mathrm{ml}=1 \mathrm{ml}$. This is the total amount needed to fill a non-adjusted device. The VAP system was prepared and flushed with heparinized saline $(50 \mathrm{IU} / \mathrm{mL})$. A distal branch of the extrahepatic portal circulation (jejunal or splenic vein) was selected based on accessibility and size (Fig. 1). Two polyglecaprone 25 (Monocryl 4-0, Johnson \& Johnson International, Amersfoort, The Netherlands) stay-sutures and a Rummel tourniquet (Fig. 1a, left) were placed around the vessel to fixate the vessel and to prevent bleeding. A stab incision was made between both sutures and elongated to approximately $5 \mathrm{~mm}$ over the length of the vein. With the aid of a vein hook (Fig. 1a, middle) the rounded tip of the VAP catheter was inserted into the vein and carefully fed towards the main stem of the extrahepatic portal vein, just one to two centimetres proximal to the hepatic entrance. The position was checked by palpation and the VAP catheter was fixed at the insertion site using a Chinese finger trap suture technique with polypropylene (Prolene 4-0, Johnson \& Johnson, Amersfoort, The Netherlands) (Fig. 1a, right). The tourniquet was removed and the preplaced staysutures, one distal and one proximal to the catheter insertion, were tied. The VAP system was repeatedly flushed with heparinized saline $(50 \mathrm{IU} / \mathrm{mL})$.
The port of the VAP system was placed in a subcutaneous pocket lateral to the caudal part of the midline incision. A stab incision was made in the abdominal wall and the extravenous part of the catheter was inserted through the incision and connected to the portal outside the abdomen. The portal was fixated to the muscular fascia with three polypropylene (Prolene $2-0$, Johnson \& Johnson, Amersfoort, The Netherlands) interrupted sutures (Fig. 1b). The VAP system was flushed again to confirm patency and the subcutaneous pocket was closed with single interrupted polyglecaprone 25 sutures. A 19G gripper needle (reference number: 21-3280-24, Smiths Medical Nederland B.V., Rosmalen, The Netherlands) was placed percutaneously into the port to obtain venous access for the liver cell infusions and to enable portal venous pressure measurements (Fig. 1c). The system was flushed with saline to confirm patency. The abdomen was closed routinely.

\section{Portal pressure measurements}

We explored the possibility to measure the pressure in the portal vein directly and non-invasively via the VAP system. For this purpose, an extension tubing was connected to the gripper needle in the subcutaneous portal during surgery in two dogs. Venous pressure was

A
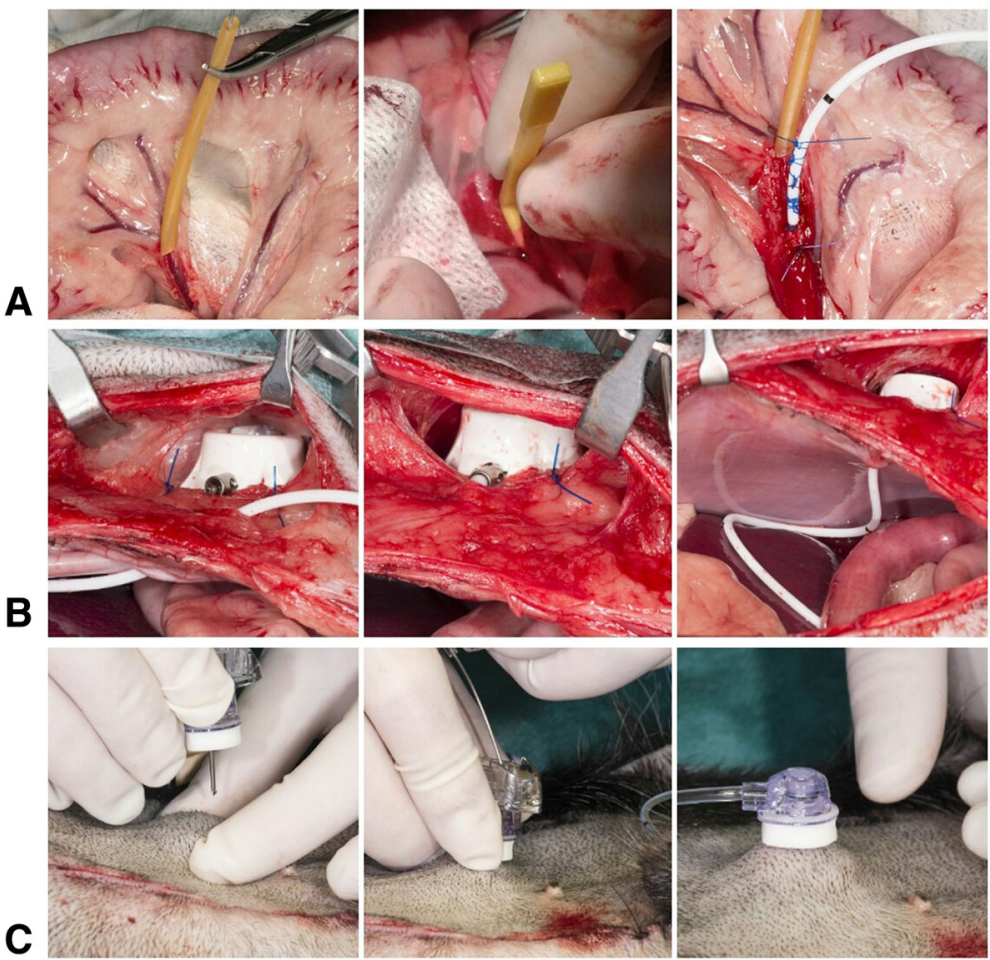

Fig. 1 Surgical implantation of a vascular access port (VAP) into the portal venous circulation of the liver: a Vascular access catheter implantation: selection and isolation with a Rummel tourniquet of a jejunal vein in the omentum ( $\mathrm{A}$, left); usage of a vein hook to obtain access and introduce the catheter into the jejunal vein (A, middle); fixation of the catheter using a Chinese finger trap suture (A, right). $\mathbf{b}$ Subcutaneous implantation of the portal. c Percutaneous placement of the gripper needle into the subcutaneous portal 
measured by a water column method in centimetres $\mathrm{H}_{2} \mathrm{O}$ and electronically by a Merit Medical single transducer set (Gabarith ${ }^{\oplus}$ PMSET 1DT-XX 1rose) connected to a Datex-Ohmeda S5 Anaesthesia Monitor in millimetres $\mathrm{Hg}$. In both cases, the level of the right atrium was used as zero reference.

\section{Maintenance and patency checks of VAP}

Patency of the VAP system was checked by flushing portal and catheter with saline once daily on the first 2 days after surgery before and after infusing cells through the VAP into the portal bloodstream. Images of the portal vein and the tip of the catheter were obtained by Bmode imaging and colour Doppler was applied to check for hepatopetal flow during infusion. The gripper needle was removed 5 days after surgery.

Subsequently, patency was checked by flushing the VAP system once a month. The skin overlying the portal was clipped, locally anesthetized with a combined lidocaine and prilocaine ointment EMLA Cream 5\% (AstraZeneca, Den Haag, The Netherlands) and routinely disinfected. A 19G gripper needle (reference number: 21-3468-24, Smiths Medical Nederland B.V) was inserted percutaneously into the subcutaneous portal. Using a syringe, $5 \mathrm{ml}$ of blood was withdrawn and the catheter was subsequently flushed with $10 \mathrm{ml}$ of saline. Patency of the portal vein and the position of the intravenous catheter were also checked with abdominal ultrasonography. After each use of the VAP, a heparin lock was placed by infusion of $5 \mathrm{ml}$ of heparinized saline (100 IU/ml).

\section{Results}

\section{VAP system implantation}

In dog no. 1, the VAP catheter was successfully inserted via a mesenteric jejunal vein. In dog no. 2 and 3 mesenteric jejunal vein insertion was unsuccessful, as the jejunal veins proved to be too small in diameter. Therefore, in dogs no. 2 and 3 the VAP insertion was performed in a splenic vein without any problems.

\section{Portal pressure measurements}

In dog no. 2 and 3, portal pressure could be measured intraoperatively via the VAP system both via a water column method and electronically. Portal pressure was 13 $\mathrm{cmH}_{2} \mathrm{O}$ and $10 \mathrm{mmHg}$, respectively for dog no. 2, and $13 \mathrm{cmH}_{2} \mathrm{O}$ and $14 \mathrm{mmHg}$ for dog no. 3 .

\section{Post-operative complications}

Dogs no. 1 and 2 developed a haemoabdomen within $24 \mathrm{~h}$ after surgery, confirmed with ultrasound guided abdominocenthesis. Explorative celiotomy showed diffuse bleeding from the hepatic lobectomy site, which was controlled with additional electrocoagulation and ligation. Both dogs recovered completely with additional supportive care including packed red cell and plasma transfusions. Results of blood analysis are presented in Table 1. All three dogs experienced a decrease in haematocrit, plasma total protein and albumin levels consistent with blood loss.

\section{Postoperative use of the VAP system}

In all dogs, portal vein injections (Fig. 2.) and blood sampling (Fig. 3.) via the VAP system using the gripper needle did not require sedation and did not result in any clinical adverse events. Withdrawal of portal blood via the VAP was possible up to 3 months after surgery in dog no. 2 , and in dog no. 1 and no. 3 up to 1 month after surgery.

\section{VAP system complications}

In all dogs the VAP system became dysfunctional one to 4 months after placement. This did not result in any adverse clinical signs. In dog no. 1 routine ultrasonographic evaluation 2 months after placement showed the catheter tip to be dislocated from the proximal position in the portal vein. The exact location of the VAP catheter was determined with additional abdominal radiographs (Fig. 4a,b) and computed tomography (PhilipsSecura, single-slice helical CT scanner; Philips NV, Eindhoven, The Netherlands). The catheter was lying free within the abdominal cavity. In dogs no. 2 and 3 the catheter became dysfunctional four and 1 month after placement, respectively, because of an obstruction due to thrombus formation at the tip of the catheter, extending into the lumen of the portal vein (Fig. 5). After the loss of VAP system functionality, the VAP was removed in all dogs during celiotomy without complications at 107, 156 and 142 days after implantation for dogs no. 1, 2 and 3, respectively. After removal of the catheter, the vein was ligated distal to the insertion site.

\section{Discussion}

This study describes the implantation and use of a commercially available VAP system in the portal venous system of three dogs. The VAP system was successfully used for administration of cell suspensions in the portal vein and blood sampling from the portal vein for a minimum period of 1 month after placement. It was demonstrated that also direct portal blood pressure measurements during surgery are possible with the use of the VAP system, and the results are within the reported physiological range for dogs [13, 14].

In contrast to percutaneous venous catheters, VAP systems have a subcutaneous portal access that offers better protection against external trauma, such as automutilation, and contamination. Their potential durability enables continuous intravenous access for a longer time period, both for clinical and research purposes [11, 12, 
Table 1 Blood parameters in three dogs as measured pre-operatively (day of surgery) and up to three months post-operatively (PO)

\begin{tabular}{|c|c|c|c|c|c|c|c|c|}
\hline & Dog & Day of surgery & 1 day PO & 2 days $\mathrm{PO}$ & 3 days $\mathrm{PO}$ & 7 days $\mathrm{PO}$ & 1 month $\mathrm{PO}$ & 3 months $\mathrm{PO}$ \\
\hline \multirow{3}{*}{$\begin{array}{l}\text { Hematocrit } \\
\text { (Rl: } 0.42-0.61 \mathrm{~L} / \mathrm{L})\end{array}$} & 1 & 0.45 & 0.39 & 0.20 & 0.35 & 0.37 & NA & 0.47 \\
\hline & 2 & 0.43 & 0.23 & 0.35 & 0.36 & 0.41 & 0.38 & 0.43 \\
\hline & 3 & 0.50 & 0.29 & 0.32 & 0.36 & 0.45 & 0.48 & 0.45 \\
\hline \multirow{3}{*}{$\begin{array}{l}\text { Platelets } \\
\text { (RI: 144-603 10^9/L) }\end{array}$} & 1 & 287 & 212 & 57 & NA & 205 & 468 & 372 \\
\hline & 2 & 556 & 70 & 96 & 107 & 164 & 299 & 178 \\
\hline & 3 & 569 & 116 & 124 & 148 & 136 & 244 & NA \\
\hline \multirow{3}{*}{$\begin{array}{l}\text { aPTT } \\
\text { (RI: } 13.2-18.2 \text { s.) }\end{array}$} & 1 & 17.2 & 15.7 & 19.8 & 27.9 & 18.7 & 14.1 & 15.9 \\
\hline & 2 & 15.9 & NA & 28.3 & NA & 17.1 & 15.4 & 15.1 \\
\hline & 3 & 13.2 & 16.4 & 18.4 & NA & 13.3 & 13.2 & 14.3 \\
\hline \multirow{3}{*}{$\begin{array}{l}\text { PT } \\
\text { (RI: 7.2-9.9 s.) }\end{array}$} & 1 & 7.4 & 9.6 & 9.8 & 9.7 & 9.7 & 7.9 & 7.6 \\
\hline & 2 & 7.7 & NA & 16.6 & NA & 9.0 & 8.3 & 7.9 \\
\hline & 3 & 7.2 & 8.7 & 9.2 & NA & 7.7 & 7.8 & 7.4 \\
\hline \multirow{3}{*}{$\begin{array}{l}\text { Fibrinogen } \\
\text { (Rl: } 1.0-2.7 \mathrm{~g} / \mathrm{L})\end{array}$} & 1 & 2.9 & 3.2 & 3.3 & 4.7 & 4.4 & 4.3 & 2.4 \\
\hline & 2 & 4.8 & NA & 2.3 & NA & 1.7 & 2.1 & 2.0 \\
\hline & 3 & 2.2 & 3.5 & 4.4 & NA & 2.2 & 1.8 & 2.5 \\
\hline \multirow{3}{*}{$\begin{array}{l}\text { Total Protein } \\
\text { (Rl: } 55-72 \mathrm{~g} / \mathrm{L})\end{array}$} & 1 & 65 & 42 & 35 & 40 & 55 & NA & 72 \\
\hline & 2 & 55 & 32 & 39 & 49 & NA & 53 & 55 \\
\hline & 3 & 61 & 39 & 49 & 50 & 65 & 61 & 62 \\
\hline \multirow{3}{*}{$\begin{array}{l}\text { Albumin } \\
\text { (Rl: } 26-37 \mathrm{~g} / \mathrm{L})\end{array}$} & 1 & 31 & 19 & 16 & 16 & 21 & NA & 34 \\
\hline & 2 & 29 & 15 & 20 & 25 & NA & 28 & 28 \\
\hline & 3 & 30 & 20 & 23 & 23 & 31 & 29 & 29 \\
\hline
\end{tabular}

Abbreviations: $R /$ reference interval, aPT activated partial thromboplastin time, $P T$ prothrombin time, NA not available

15-18]. This study demonstrates their effectiveness in obtaining easy and long term access to parts of the cardiovascular system that are out of reach of percutaneous catheters. Therefore, VAP systems could be useful in a wide range of clinical and research applications in dogs such as prolonged or frequent intravenous administration of therapeutics, blood pressure measurements or blood sampling.

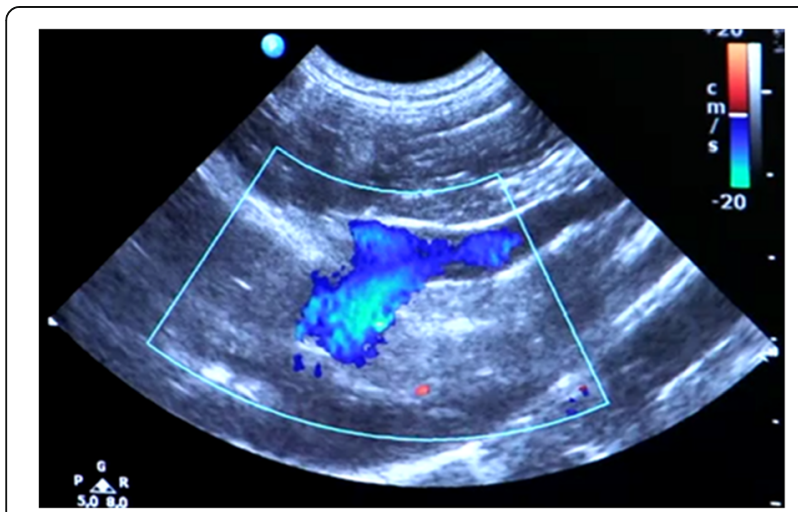

Fig. 2 Doppler-enhanced ultrasonography visualizes hepatopetal flow in the portal vein at the level of the porta hepatis during infusion of liver cell suspensions via the vascular access port
For access to the portal venous system both the use of a jejunal vein and a splenic vein as insertion site for the VAP catheter have been advocated $[17,18]$. The use of a five to seven French diameter catheter has been suggested in dogs [18]. The 5.8 French diameter catheter that was used in this study still appeared too large for

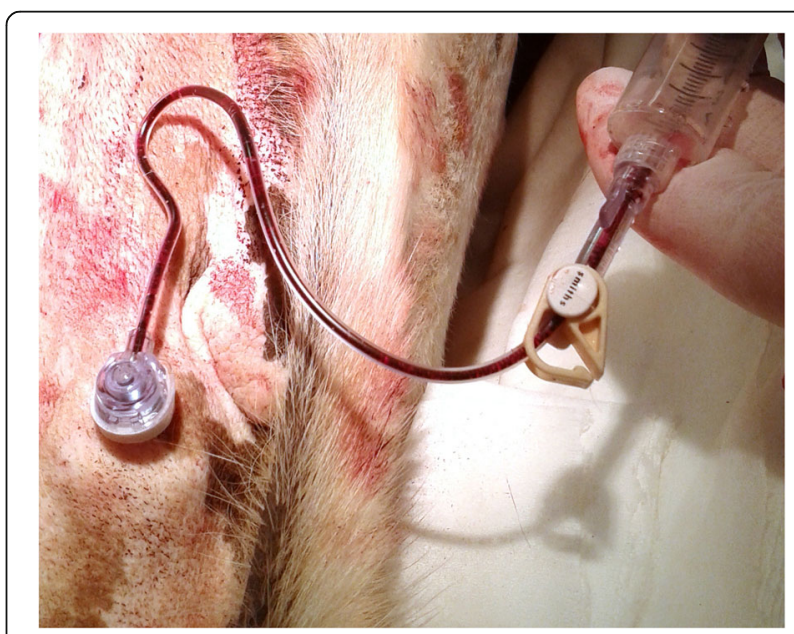

Fig. 3 Sampling of portal blood using the gripper needle inserted percutaneously in the subcutaneous portal in a dog 

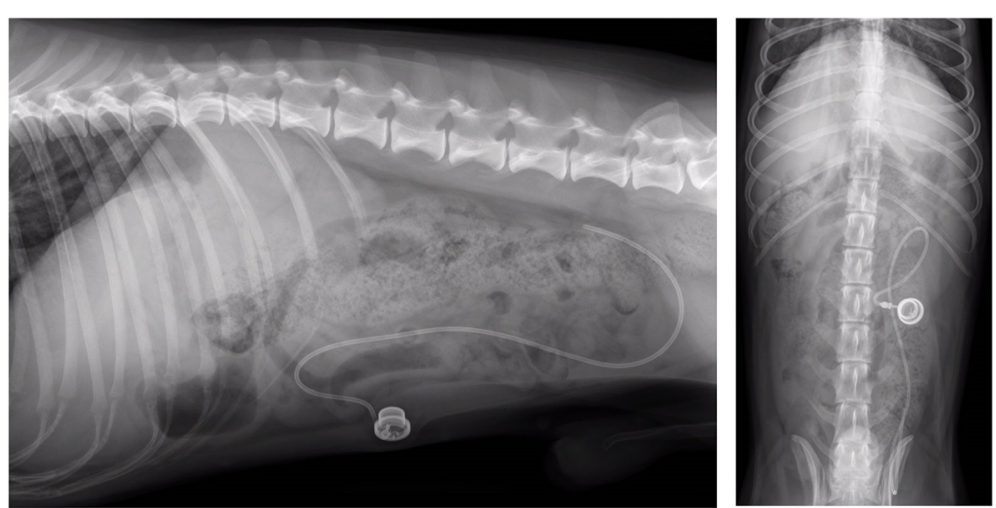

Fig. 4 Vascular access port (VAP) system complication in dog no. 1. Abdominal radiographs show the venous catheter of the VAP system dislocated from the portal vein two months after surgical implantation. The tip of the catheter is located caudodorsally in the abdomen

insertion in a jejunal vein in two medium sized dogs. However, a splenic vein offered a good alternative for catheter insertion when the jejunal veins were too small.

Postoperatively, haemoabdomen was a serious complication in dog no.1 and no.2. In both dogs no signs of a local bleeding were observed due to ineffective ligation of large hepatic vessels and both showed coagulopathy shortly after surgery (Table 1). Retrospective evaluation of the procedures noticed an extensive use of heparin in both dogs: heparinised sodium chloride $0.9 \%$ with a concentration of heparin of $50 \mathrm{IU} / \mathrm{ml}$ was used to flush the IV catheters (VAP system, peripheral and central venous catheters) very often. The exact amounts of administered heparin were not documented but overuse could have iatrogenically caused a hypocoagulable state. Therefore in dog no. 3 the heparin concentration in saline used to flush all catheters per-operatively was reduced from 50 to $10 \mathrm{IU} / \mathrm{ml}$ and flushing volumes were minimized. No

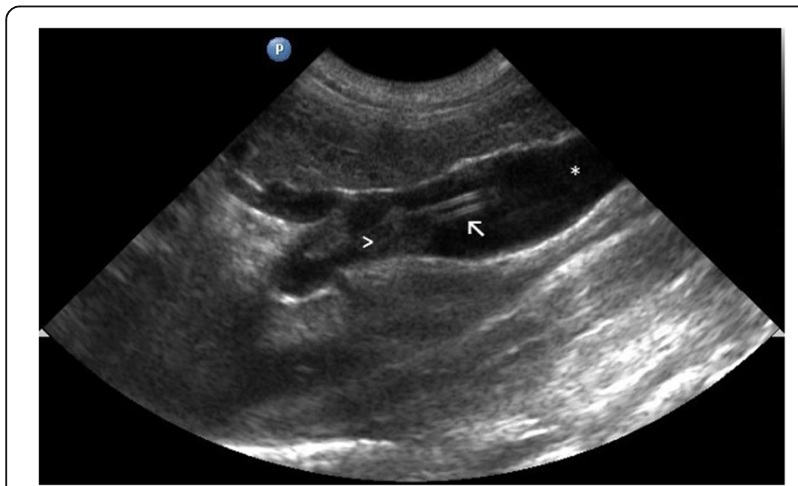

Fig. 5 Vascular access port (VAP) system (PORT-A-CATH ${ }^{\circledR}$ POWER system; Smiths Medical, Ashford, Kent, UK) complication in dog no. 2. B-mode image shows thrombus formation (arrow head) at the level of the catheter tip (arrow) four months after surgical implantation. The tip of the catheter is situated in the portal vein (asterisk) postoperative coagulopathy or other complications were noticed in dog no. 3 .

Infection of the VAP system is one of the most common complications in human patients [19], and in animals [5, 12, 15, 17, 18]. Monthly microbial cultures of specimens from the port revealed a rate of one infection per 200 catheter days [17]. In this study no microbial cultures were performed, but no clinical signs indicating infection (e.g. fever, leucocytosis) were encountered in our dogs. In future applications, microbial cultures could be useful to detect early (subclinical) infections.

Dislocation of the catheter or port has been described as a complication in both veterinary and human use $[8$, $11,18,19]$. In dog no. 1 the catheter was dislocated from the prolene suture, which was still intact. It is unclear why the suture did not hold in this dog, but dislocation of the catheter may have been related to the suture technique, the thermoplastic nature of the polyurethane catheter or motility of the intestines [20]. The fact that the catheters positioned in the splenic vein did not dislocate supports the causative role of intestinal motility on the dislocation. For future VAP use in the portal system in dogs we would therefore recommend a splenic vein as first choice insertion site.

Although no adverse clinical signs developed by the thrombosis at the tip of two VAP catheters, deep venous thrombosis of the portal vein with complete intraluminal obstruction can lead to portal hypertension and hepatic embolization [21]. Conceivably, we noticed the complication early in its development before portal hypertension could occur. Few cases of VAP system-associated venous thrombosis have been reported in veterinary medicine $[11,18]$. In an experimental study with a VAP system in the portal system no thrombosis of the portal vein was reported [17]. Differences between studies in the occurrence of thrombi may be explained by differences in species, the applied VAP system, its vascular location, the applied (chemo)therapeutics, time span and 
catheter maintenance procedures. In this study the maintenance recommendations of the manufacturer were followed: a monthly catheter flush with $5 \mathrm{~mL}$ of heparinized $(100 \mathrm{IU} / \mathrm{mL})$ normal saline. Instead, in the study without reported thrombosis [17] the system was flushed weekly with normal saline $(3 \mathrm{~mL})$ followed by a heparin lock of $1 \mathrm{~mL}$ of heparinized $(1000 \mathrm{IU} / \mathrm{mL})$ saline. More research is needed to specify whether more frequent flushing and/or increased heparin concentrations are most effective in decreasing catheter-associated thrombosis in canine VAP applications.

In our study, the presence of thrombi in the main stem of the portal vein of two dogs urged the premature removal of the VAP system. In human medicine, catheter removal because of thrombus formation is only considered if anticoagulation therapy fails or is contraindicated [22-26]. Because of missing evidence supporting successful use of thrombolytics in canine venous thrombosis and potential risk of inducing bleeding tendencies [27-30], it was decided to remove the VAP systems. Thrombectomy during celiotomy for removal of the VAP system was considered too risky [27]. After removal of the VAP system the dogs had an uneventful recovery. Further research is necessary to determine the optimal maintenance regime to prevent catheter-associated thrombosis in VAP systems in the canine portal vein.

Although the number of dogs in our study was limited, the results of this study could benefit other veterinary clinicians and researchers.

\section{Conclusions}

This pilot study demonstrates that a VAP system can be effectively applied in dogs to obtain long term access to the portal venous system for venous pressure measurements, repeated infusions, and blood sampling. However, the long term presence of the device may increase the risk for dislodgement or thrombosis complications of the port.

\section{Abbreviations \\ aPTT: Activated partial thromboplastin time; PT: Prothrombin time; VAP: Vascular access port}

\section{Acknowledgements}

The authors would like to thank Ivo Sullot from Smiths Medical for his technical assistance, and Inge van Duiven, Ronald Jan Corbee, and the staff of the Intensive Care Unit of the Department of Clinical Sciences of Companion Animals, Faculty of Veterinary Medicine, Utrecht University for their clinical assistance.

Preliminary results were presented as a poster at the ECVS Annual Scientific Meeting, Edinburgh, 13-15 July 2017.

\section{Authors' contributions}

HK, BAS and AK designed the study. KSdN, HSK, GVS and AK performed surgery and/or clinical care of the dogs, and collected and interpreted the data. IA performed anaesthesia and peri-operative monitoring of the dogs. JHR performed postoperative monitoring and intensive care. LVB performed diagnostic imaging and interpretation. KSdN, HSK and AK drafted the manuscript. All authors gave substantial input to the manuscript. All authors read and approved the final manuscript.

\section{Funding}

The original research project was funded by the Dutch Research Council NWO ZON/MW (116004121). NWO ZON/MW had no role in the design of the study and collection, analysis, and interpretation of data and in writing the manuscript

\section{Availability of data and materials}

All data generated or analysed during this study are included in this published article.

\section{Ethics approval and consent to participate}

All procedures were approved by Utrecht University's Ethical Committee, as required under Dutch legislation (DEC number 2014.III.12.112).

\section{Consent for publication}

Not applicable.

\section{Competing interests}

The authors declare that they have no competing interests.

Received: 5 March 2018 Accepted: 30 June 2019

Published online: 11 July 2019

References

1. Brincker $H$, Saeter $G$. Fifty-five patient years' experience with a totally implanted system for intravenous chemotherapy. Cancer. 1986;57:1124-9.

2. Soo KC, Davidson TI, Selby P, Westbury G. Long-term venous access using a subcutaneous implantable drug delivery system. Ann R Coll Surg Engl. 1985; 67:263-5.

3. van der Staak F, Bokkerink J, Lippens R, Severijnen R. Totally implantable systems for intravenous drug delivery. Experiences in children with cancer Z.Kinderchir. 1986:41:39-42.

4. Morris. M, Phares K, Zaccardelli D, Uihelyi MR. A novel catheter system for totally implantable intravenous drug therapy: assessment of catheter function and patency with trepostinil therapy. J Vasc Access [Internet. 2008; 9:20-7.

5. Culp WTN, Mayhew PD, Reese MS, Duda L, Glassman MM, Brown DC. Complications associated with use of subcutaneous vascular access ports in cats and dogs undergoing fractionated radiotherapy: 172 cases (1996-2007). J Am Vet Med Assoc. 2010;236:1322-7.

6. Mayer MN, Grier CK, Yoshikawa H, Ringwood PB. Complications associated $W /$ the use of VAPs in dogs receiving external beam RT. J Am Vet Med Assoc. 2008;233:96-103.

7. Evans KL, Smeak DD, Couto CG, Hammer AS, Gaynor JS. Comparison of two indwelling central venous access catheters in dogs undergoing fractionated radiotherapy. Vet Surg. 1994;23:135-42.

8. Darwish AA, Sokal E, Stephenne X, Najimi M. de Ville de Goyet J, Reding R. permanent access to the portal system for cellular transplantation using an implantable port device. Liver Transplant. 2004;10:1213-5.

9. Favier RP, Spee B, Schotanus BA, van den Ingh TSGAM, Fieten $H_{\text {, }}$ Brinkhof $B$, et al. COMMD1-deficient dogs accumulate copper in hepatocytes and provide a good model for chronic hepatitis and fibrosis. PLoS One. 2012;7:1-8.

10. Große-Siestrup C, Lajous-Petter AM. Totally implantable catheter system in the dog. J Investig Surg. 1990;3:373-85.

11. Cahalane AK, Rassnick KM, Flanders JA. Use of vascular access ports in femoral veins of dogs and cats with cancer. J Am Vet Med Assoc. 2007;231: 1354-60.

12. Valentini F, Fassone F, Pozzebon A, Gavazza A, Lubas G. Use of totally implantable vascular access port with mini-invasive Seldinger technique in 12 dogs undergoing chemotherapy. Res Vet Sci Elsevier Ltd. 2013:94:152-7.

13. Lee KCL, Lipscomb VJ, Lamb CR, Gregory SP, Guitian J, Brockman DJ. Association of portovenographic findings with outcome in dogs receiving surgical treatment for single congenital portosystemic shunts: 45 cases (2000-2004). J Am Vet Med Assoc. 2006;229:1122-9.

14. Sakamoto $Y$, Sakai M, Watari T. Three minimally invasive methods of measuring of portal vein pressure in healthy dogs. J Vet Med Sci. 2012;74: 1299-302. 
15. Aubert I, Abrams-Ogg ACG, Sylvestre AM, Dyson DH, Allen DG, Johnstone IB. The use of vascular access ports for blood collection in feline blood donors. Can J Vet Res. 2011;75:25-34.

16. Guérios SD, Silva DM, Souza CHM, Bacon NJ. Surgical placement and management of jugular vascular access ports in dogs and cats: description of technique. Implant quirúrgica y gestión catéter venoso Cent en la vena yugular perros y gatos descripción la técnica. 2015;28:165-71.

17. Sutyak JP, Lee YH, Perry BA, Stern W, Makhey V, Sinko PJ. Improved longevity and functionality of a canine model providing portal vein and multi-site intestinal access. Comp Med. 2000;50:167-74

18. Swindle MM, Nolan T, Jacobson A, Wolf P, Dalton MJ, Smith AC. Vascular access port (VAP) usage in large animal species. Contemp Top Lab Anim Sci. 2005:44:7-17.

19. Denny DF. Placement and management of long-term central venous access catheters and ports. Am J Roentgenol. 1993;161:385-93.

20. Song EK, Mann FA, Wagner-Mann CC. Comparison of different tube materials and use of chinese finger trap or four friction suture technique for securing gastrostomy, jejunostomy, and thoracostomy tubes in dogs. Vet Surg. 2008;37:212-21.

21. Chawla YK, Bodh V. Portal vein thrombosis. J Clin Exp Hepatol Elsevier Ltd. 2015;5:22-40.

22. Kovacs MJ, Kahn SR, Rodger M, Anderson DR, Andreou R, Mangel JE, et al. A pilot study of central venous catheter survival in cancer patients using lowmolecular-weight heparin (dalteparin) and warfarin without catheter removal for the treatment of upper extremity deep vein thrombosis (the catheter study). J Thromb Haemost. 2007:5:1650-3.

23. Kearon C, Akl EA, Comerota AJ, Prandoni P, Bounameaux H, Goldhaber SZ, et al. Antithrombotic therapy for VTE disease: antithrombotic therapy and prevention of thrombosis, 9th ed: American College of Chest Physicians evidence-based clinical practice guidelines. Chest, vol. 141: The American College of Chest Physicians; 2012. p. e419S-96S.

24. Debourdeau P, Farge D, Beckers M, Baglin C, Bauersachs RM, Brenner B, et al. International clinical practice guidelines for the treatment and prophylaxis of thrombosis associated with central venous catheters in patients with cancer. J Thromb Haemost. 2013;11:71-80.

25. Fallouh N, McGuirk HM, Flanders SA, Chopra V. Peripherally inserted central catheter-associated deep vein thrombosis: a narrative review. Am J Med Elsevier Inc. 2015;128:722-38.

26. Jasti N, Streiff MB. Prevention and treatment of thrombosis associated with central venous catheters in cancer patients. Expert Rev Hematol. 2014;7: 599-616.

27. Dunn ME. Thrombectomy and thrombolysis: the interventional radiology approach. J Vet Emerg Crit Care. 2011;21:144-50.

28. Lunsford KV, Mackin AJ. Thromboembolic therapies in dogs and cats: an evidence-based approach. Vet Clin North Am - Small Anim Pract. 2007;37: 579-609.

29. Respess M, O\&apos;Toole TE, Taeymans O, Rogers CL, Johnston A, Webster CRL. Portal vein thrombosis in 33 dogs: 1998-2011. J Vet Intern Med 2012; 26:230-237.

30. Langston C, Eatroff A, Poeppel K. Use of tissue plasminogen activator in catheters used for extracorporeal renal replacement therapy. J Vet Intern Med. 2014:270-6.

\section{Publisher's Note}

Springer Nature remains neutral with regard to jurisdictional claims in published maps and institutional affiliations.

Ready to submit your research? Choose BMC and benefit from:

- fast, convenient online submission

- thorough peer review by experienced researchers in your field

- rapid publication on acceptance

- support for research data, including large and complex data types

- gold Open Access which fosters wider collaboration and increased citations

- maximum visibility for your research: over $100 \mathrm{M}$ website views per year

At BMC, research is always in progress.

Learn more biomedcentral.com/submissions 